\title{
MODERNIZATION OF CONTROL SYSTEM OF A1756 MACHINE FOR PLASMA-POWDER SURFACING
}

\author{
E.F. PEREPLYOTCHIKOV, I.A. RYABTSEV, Yu.N. LANKIN, V.F. SEMIKIN and P.P. OSECHKOV \\ E.O. Paton Electric Welding Institute, NASU \\ 11 Bozhenko Str., 03680, Kiev, Ukraine. E-mail: office@paton.kiev.ua
}

\begin{abstract}
Given are the results of modernization of control system of A1756 machine for plasma-powder surfacing. New control system allows for complete automating of surfacing process as well as optimizing consumption of filler powder and minimizing its loss. Control of surfacing process is carried out with the help of programmer, designed using PIC16F886 (Microchip) microcontroller and alphanumeric OLED indicator WEH1601A (Winstar). Microprocessor block of the programmer allows for setting the parameters of time characteristics for surfacing current and powder consumption and their processing in process of program control. Scheme of programmer connection to A1756 machine with capability of operation switching from programmer as well as in simple design mode was developed and built. The programmer allows for carrying out setting of modes, providing good bead formation during automatic plasma-powder surfacing, quality filling of crater and minimum loss of filler powder. 2 Ref., 7 Figures.
\end{abstract}

Key words : plasma-powder surfacing, surfacing machine, control system, powder consumption, surfacing mode, programmer

Characteristics of transfer and melting of filler material in plasma-powder surfacing are not directly related with current and arc voltage and being mainly determined by mass feed rate and fractional composition of filler powder as well as its physical properties. An important problem, considering a fact of application of expensive powders from nickel- and cobalt-based alloys as well as special surfacing iron-based alloys as filler materials in plasma-powder surfacing, is optimizing of powder consumption and minimizing of its loss using this method of surfacing [1].

Powder consumption and its loss depend on design of some assemblies of surfacing equipment (powder feed, plasmatron), modes of surfacing and, to some extent, structure of part to be surfaced (geometry of surface). Loss of powder will rise, in particular, if plasmatron is located or periodically passes close to edge of part being surfaced as well as if width of substrate being surfaced is less than nozzle diameter.

Figure 1 shows a scheme of drum-type feeder, developed at the E.O. Paton Electric Welding Institute [2]. The feeder consists of sealed housing 1, hopper 6 with branch tube, drum 2 and setting mechanism, made in a form of spring loaded bush 4, being moved along the branch tube with the help of lever-screw regulator 3 . Mechanism 5 allows for controlling a level of powder in the feeder. The drum is actuated by DC motor by means of worm gear (not indicated in Figure 1). A gap between bush and drum is set in such a way that in the case of fixed drum the powder will remain in the hopper. Drum movement drags the powder and directs it in a receiving cone, from which powder is transported through tube 7 into plasmatron by transporting gas. Rate of filler powder feeding into plasmatron can be changed by means of regulation of drum rotation rate (Figure 2). Transporting gas feeds the filler powder in a gap between focusing 1 and plasma-forming 2 nozzles.

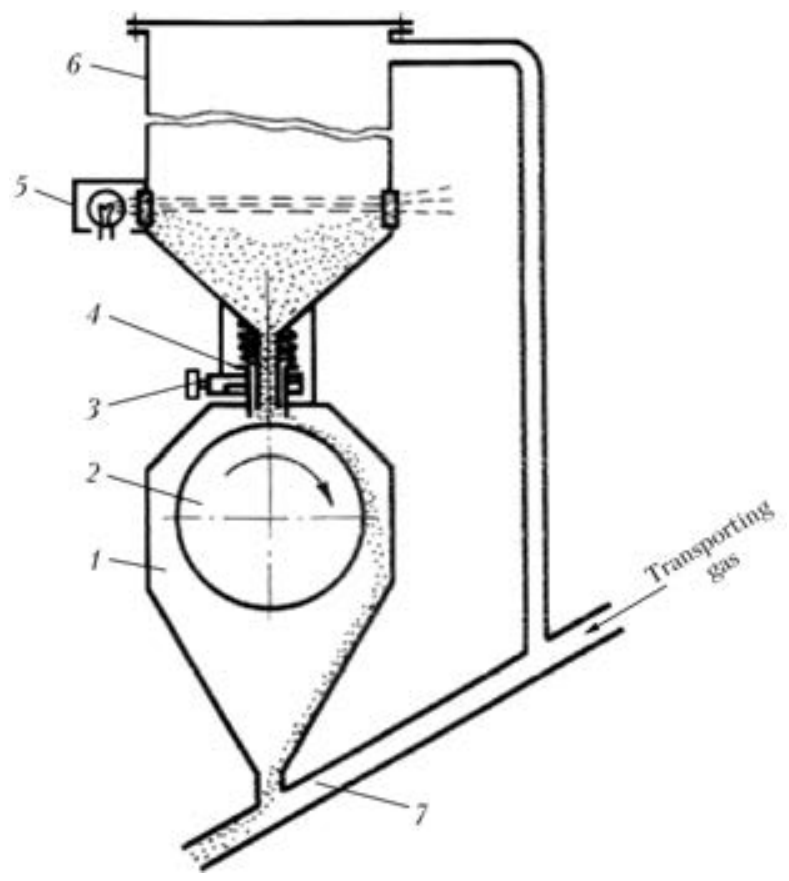

Figure 1. Scheme of drum feeder for filler powder feed (designations see in the text) 


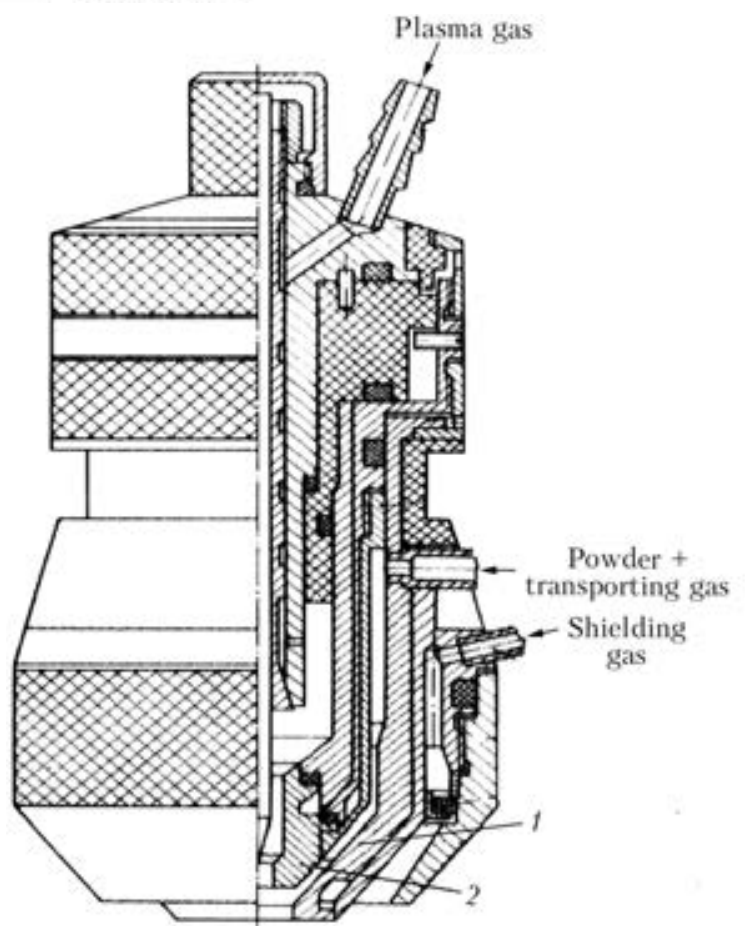

Figure 2. Plasmatron A1756.05 for plasma-powder surfacing: 1 - focusing; 2 - plasma-forming nozzle

The plasmatron has four variants of combination of plasma forming and focusing nozzles $d_{\mathrm{pl}}+$ $+d_{\mathrm{f}}: 2+4 ; 3+6 ; 4+7.5 ; 5+9 \mathrm{~mm}$, that also allows for regulating powder feed rate. Surfacing
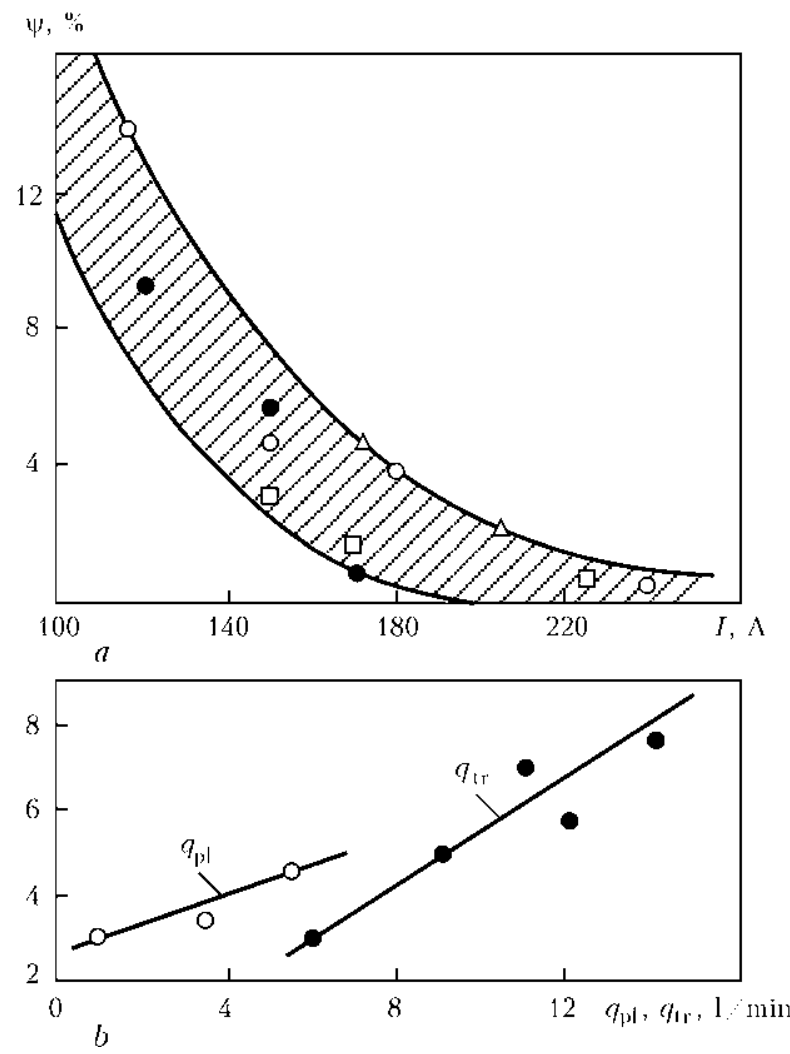

Figure 3. Dependence of coefficient of powder loss $\psi$ on surfacing current $I(a)$ and consumption of plasma $q_{\mathrm{pl}}$ and transporting $q_{\operatorname{tr}}$ gases [1] $(b) ; a-$ powder feed: -1.2 ; $\mathrm{O}-2.0 ; \square-3.5 ; \Delta-6 \mathrm{~kg} / \mathrm{h} ; b-2 \mathrm{~kg} / \mathrm{h}$
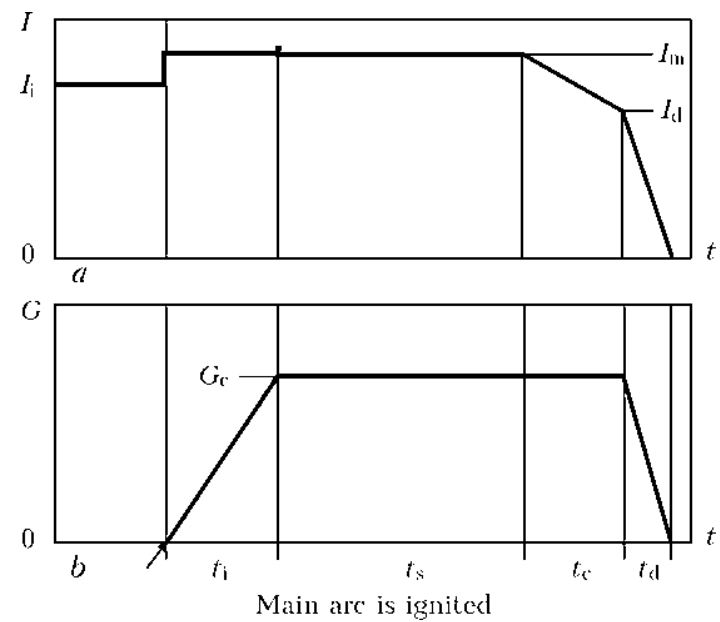

Figure 4. Cyclogram of process of plasma-powder surfacing: $a$ - surfacing current; $b-$ powder consumption; $I_{\mathrm{i}}-$ current of indirect arc; $I_{\mathrm{m}}-$ current of main arc; $I_{\mathrm{d}}-$ current at the moment of beginning of drop of powder feed rate; $G_{\mathrm{c}}-$ maximum level of powder consumption (feed rate); $t_{\mathrm{i}}$ - duration of increment; $t_{\mathrm{s}}$ - duration of soaking in steady process; $t_{\mathrm{c}}-$ duration of correction; $t_{\mathrm{d}}-$ duration of drop

technology [1] determines a variant of optimum combination of nozzle diameters.

Intensity of surfacing current and consumption of transporting gas (Figure 3 ) are the main parameters of surfacing mode effecting consumption and loss of filler powder. Increase of intensity of surfacing current reduces filler powder loss in whole range of rates of its feed (Figure 3, $a)$, since lager amount of powder can be melted in arc as well as weld pool.

Small consumption of transporting gas (3$41 / \mathrm{min}$ ) often disturbs surfacing process due to

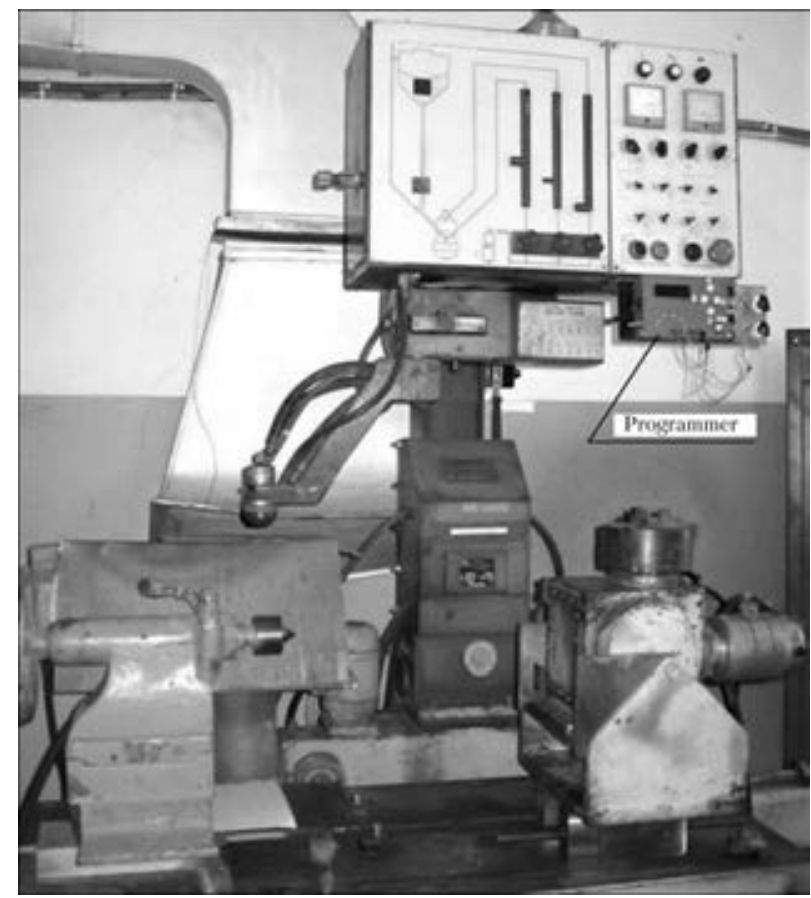

Figure 5. View of A1756 machine for plasma-powder surfacing with programmer for control of surfacing process 


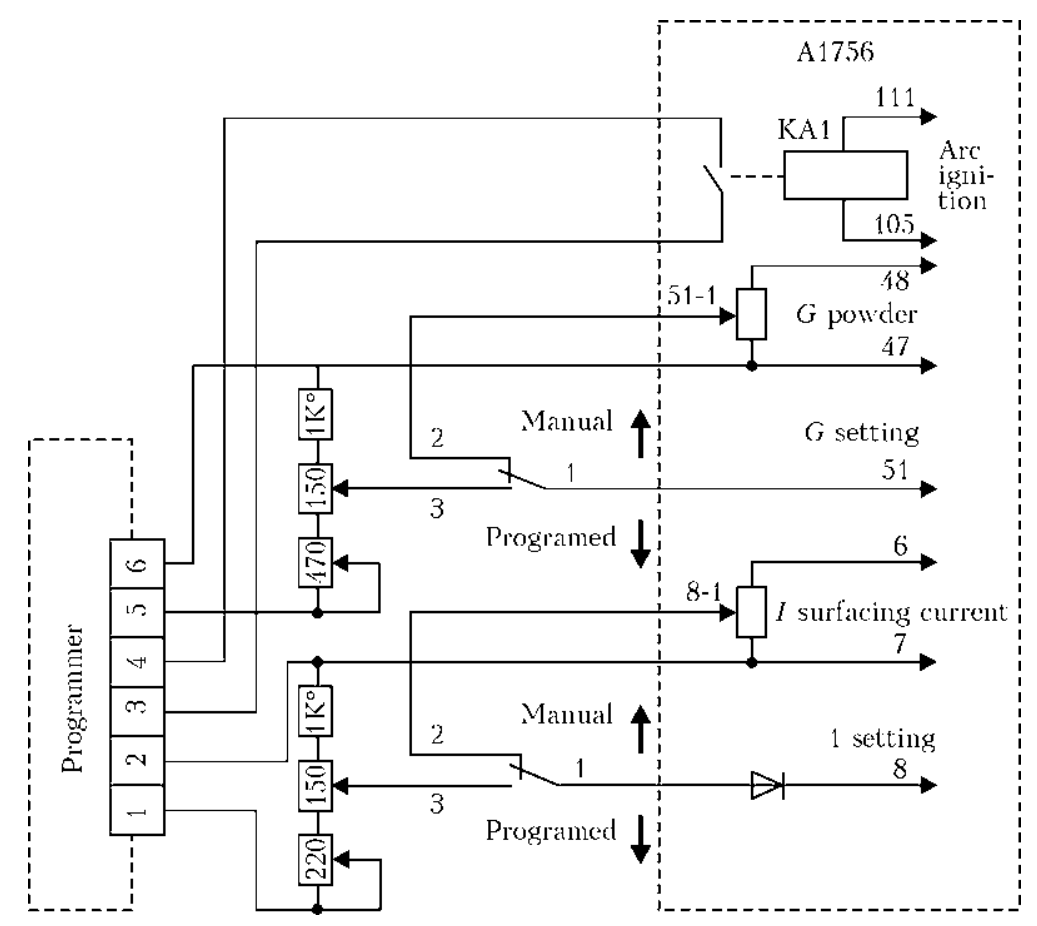

Figure 6. Principal diagram of programmer

blocking of plasmatron channels with powder. Loss of powder grows with increase of transporting gas consumption (Figure $3, b$ ) as a result of rising of initial particle rate and deterioration of conditions of their heating in the arc.

At that, according to the experience, only part of powder particles, moving in a periphery of arc column, enters the weld pool. The particles, which fall on surface being surfaced in front of or from the side of weld pool, are irreversibly lost as a result of rebound resilience from this surface. Consumption of transporting gas in the range of $6-91 / \mathrm{min}$, at which powder loss does not exceed $5-8 \%$, is supposed to be the optimum one.

There is also loss of powder at the beginning and end of surfacing process, which is difficult to be optimized and controlled, in addition to the loss, determined by technological peculiarities of steady process of plasma-powder surfacing. In theory, a cyclogram of the whole process of plasma-powder surfacing can be represented in the following way (Figure 4).
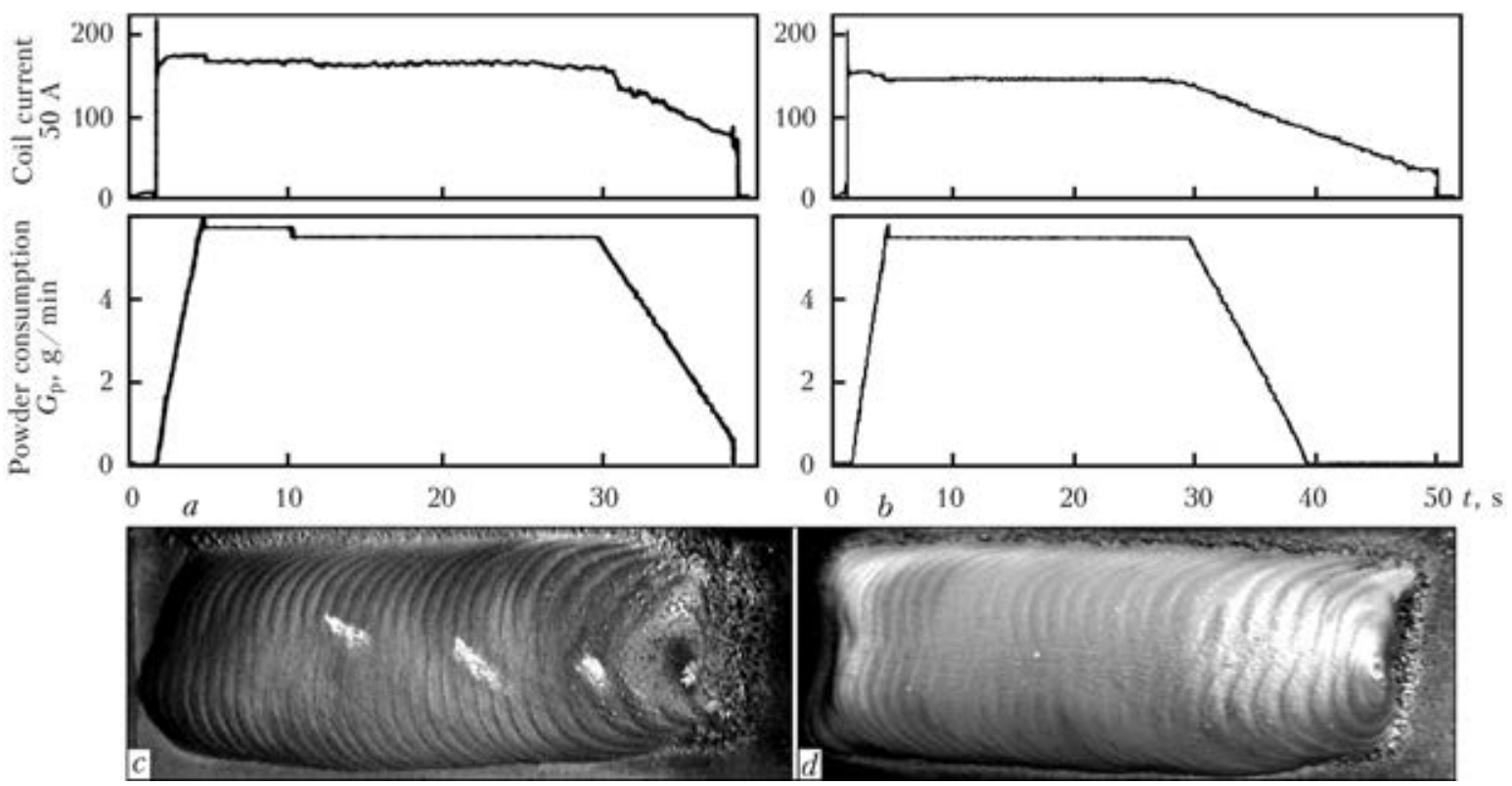

Figure 7. Time characteristics of technological parameters of surfacing $(a, b)$ and beads surfaced by these modes $(c, d)$ : $a, c-$ current and powder feed were switched-off simultaneously; $b, d-$ powder feed was stopped before current switching-off 
Feeding of filler powder should be started after main arc ignition (Figure $4, b$ ). Powder feed is increased during time $t_{\mathrm{i}}$ to value $G_{\mathrm{c}}$ determined by the technology. Crater filling is necessary to be carried out at the end of surfacing process with stepwise synchronous reduction of surfacing current and rate of powder feed.

The E.O. Paton Electric Welding Institute developed a programmer for control of plasmapowder surfacing process. It was designed with application of microcontroller PIC16F886 ( Microchip) and alphanumeric OLED indicator WEH1601A (Winstar). Microprocessor block of the programmer allows for setting the parameters of time characteristics of surfacing current and powder consumption for plasma-powder surfacing machine A1756 (Figure 5) and their optimizing in the process of program control.

Principal diagrams, printed circuit boards, structure and software were developed for the programmer. Software was adjusted for technological conditions of A1756 machine:

- technological parameters are set in actual values (surfacing current in amperes, powder consumption in $\mathrm{g} / \mathrm{min}$ );

- entered are the technological limits for setting the parameters of time characteristics 0 $250 \mathrm{~A}$ and $0-120 \mathrm{~g} / \mathrm{min}$.

Scheme of programmer connection to A1756 machine with capability of switching of operation from programmer as well as in simple design mode was developed and built (Figure 6).
The programmer was technologically tested on A1756 machine by recording the main parameters of surfacing mode, i.e. current and powder feed. Stated problem lied in development of such modes of surfacing, which would provide for minimum powder loss and quality formation of surfaced beads, including quality crater filling.

If current is switched-off simultaneously or before stopping of powder feed, this will result in bad crater filling and excessive powder loss (Figure 7, $a, c$ ).

In the case, when powder feed is stopped before current switching-off, quality cater filling is provided and powder loss is reduced to the minimum (Figure $7, b, d$ ). Beginning of drop of current and powder feed are matched in time, however, powder feed is stopped somewhat earlier (Figure 7,b).

Thus, developed programmer allows for setting the modes, providing good formation of surfaced beads, in automatic plasma-powder surfacing on A1756 machine, quality crater filling and minimum loss of filler powder.

1. Gladky, P.V., Pereplyotchikov, E.F., Ryabtsev, I.A. (2007) Plasma surfacing. Kiev: Ekotekhnologiya.

2. Gladky, P.V., Pereplyotchikov, E.F., Saprykin, Yu.I. et al. (1970) Drum feeder. USSR author's cert. 266111. Int. $\mathrm{Cl}$. 21h $30 / 17$. Otkrytiya. Izobreteniya, 11, 76 . 